\title{
Development of Highly Conductive and Corrosion-Resistant Cr-Diamond-like Carbon Films
}

\author{
Minjung Ko**, Yee Sle Jun*****, Na Rae Lee ${ }^{* * * *}$, Suhee Kang*, \\ Kyoung Il Moon (1D***, and Caroline Sunyong Lee (1D)*, \\ *Department of Materials and Chemical Engineering, Hanyang University, Ansan 15588, Korea \\ **Heat Treatment Group, Korea Institute of Industrial Technology, Siheung 15014, Korea
}

(Received May 3, 2019; Revised May 8, 2019; Accepted May 8, 2019)

\begin{abstract}
Cr-diamond-like carbon (Cr-DLC) films were deposited using a hybrid method involving both physical vapor deposition and plasma-enhanced chemical vapor deposition. DLC sputtering was carried out using argon and acetylene gases. With an increase in the DC power, the $\mathrm{Cr}$ content increased from 14.7 to 29.7 at $\%$. The $\mathrm{Cr}-\mathrm{C}$ bond appeared when the $\mathrm{Cr}$ content was 17.6 at\% or more. At a $\mathrm{Cr}$ content of 17.6 at\%, the films showed an electrical conductivity of $>363 \mathrm{~S} / \mathrm{cm}$. The current density was $9.12 \times 10^{-2}$ $\mu \mathrm{A} / \mathrm{cm}^{2}$, and the corrosion potential was $0.240 \mathrm{~V}$. Therefore, a Cr content of 17.6 at\% was found to be optimum for the deposition of the Cr-DLC thin films. The Cr-DLC thin films developed in this study showed high conductivity and corrosion resistance, and hence, are suitable for applications in separators.
\end{abstract}

Key words : Electrical conductivity, Corrosion resistance, Cr-Diamond-like carbon film, Physical vapor deposition, Plasma-enhanced chemical vapor deposition

\section{Introduction}

D iamond-like carbon (DLC) films are amorphous carbon coating films with a combination of $\mathrm{sp}^{2}$ graphite and $\mathrm{sp}^{3}$ diamond structures. DLC thin films exhibit high hardness, chemical stability, excellent abrasion resistance, and high corrosion resistance comparable to those of diamond, and hence find applications in various fields, particularly in automotive parts. Various studies have been carried out to develop automotive parts with high fuel efficiency, low friction, and high corrosion resistance. However, the insulating properties of DLC coatings limit their applications in automotive parts. In order to overcome this limitation, efforts have been made to improve the conductivity of DLC coatings by doping them with various metals such as $\mathrm{Ti}, \mathrm{Cr}, \mathrm{Cu}$, Mo, and W. However, since metals tend to ionize, they deteriorate the corrosion resistance of DLC films when doped into them. Therefore, a novel thin film deposition method should be developed to improve the electrical conductivity of

\section{${ }^{\ddagger}$ Contributed equally to this work}

Corresponding author : Caroline Sunyong Lee

E-mail : sunyonglee@hanyang.ac.kr

Tel : +82-31-400-5221 Fax : +82-31-436-8146

ORCID

https://orcid.org/0000-0001-5794-190X

${ }^{\S}$ Corresponding author: Kyung Il Moon

E-mail : kimoon@kitech.re.kr

Tel: +82-31-8084-8637 Fax: +82-31-8084-8603

ORCID

https://orcid.org/0000-0002-9398-9684
DLC films while maintaining their corrosion resistance. ${ }^{1-17)}$ DLC films with high electrical conductivity and corrosion resistance can be used as separators in automotive fuel cells. The separator serves as a channel for supplying the fuel and oxidant to the anode and cathode. It performs various functions such as collecting and delivering the generated current, transporting and removing the reaction product, and discharging the reaction heat. Graphite separators are widely used in automotive fuel cells owing to their good corrosion resistance and light weight. However, they are fragile, thick, relatively expensive, and difficult to process. Therefore, it is imperative to develop low-cost thin films with good corrosion resistance and electric conductivity. ${ }^{18-24)}$ Hence, in our previous study, we used Ti to improve the conductivity and corrosion resistance of DLC films. We also carried out the wear tests of the DLC films. The films showed high friction coefficients, and hence could not be used for automobile applications. Therefore, in this study, we employed a hybrid method involving physical vapor deposition (PVD) and plasma-enhanced chemical vapor deposition (PECVD) at room temperature for the deposition of thin films with good conductivity and corrosion resistance. The effect of the Cr content on the conductivity and corrosion resistance of the Cr-DLC thin films was investigated. The structural and chemical properties of the CrDLC thin films were investigated to determine the optimum $\mathrm{Cr}$ content. We also investigated the feasibility of obtaining thin films with excellent wear characteristics for application as separators. 


\section{Experimental Procedure}

\subsection{Deposition of the Cr-DLC films}

The substrates used in this study were a Si-wafer, STD11, and SUS304. The surface of STD11 was polished to \#200\#2000 using a sand paper. Prior to the deposition of Cr-DLC films, all the substrates were pretreated ultrasonically using methyl alcohol for about $10 \mathrm{~min}$. After loading the treated substrates into the chamber, the base pressure was reduced to $2 \times 10^{-6}$ Torr.

The Cr target (99.9\%) was cleaned for more than $30 \mathrm{~min}$ by applying a DC power in an Ar gas atmosphere in order to remove the impurities present on its surface. Plasma cleaning was carried out subsequently for $30 \mathrm{~min}$ by applying a DC-pulsed power of $550 \mathrm{~V}$ at $10 \times 10^{-3}$ Torr in an Ar gas atmosphere. To improve the adhesion between the substrate and the DLC films, a hybrid method was employed.

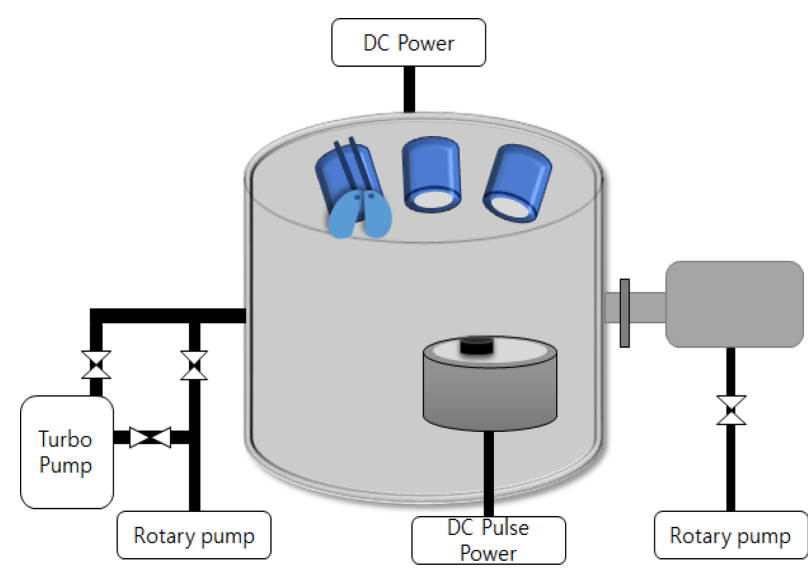

Fig. 1. Schematic of hybrid equipment.

Sample polishing and ultrasonic cleaning

$\downarrow$

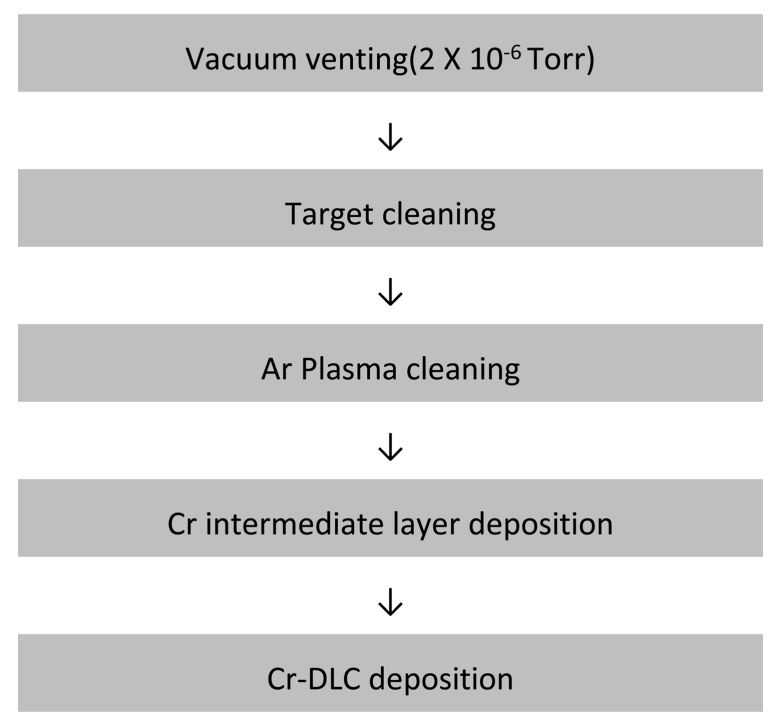

Fig. 2. Sequence of Cr-DLC thin film deposition.
Table 1. Cr-DLC Process Conditions

\begin{tabular}{cc}
\hline Process sequence & Condition \\
\hline Ar plasma cleaning & $30 \mathrm{~min}$ \\
Ar gas flow rate & $36 \mathrm{sccm}$ \\
Cr intermediate layer deposition & $15 \mathrm{~min}$ \\
Ar gas flow rate & $40 \mathrm{sccm}$ \\
& \\
Cr-DLC deposition & $1-3 \mathrm{~h}$ \\
Pressure & $2 \times 10^{-6} \mathrm{Torr}$ \\
Ar : $\mathrm{C}_{2} \mathrm{H}_{2}$ flow rate & $75: 3$ \\
DC pulse power (Voltage) & $-500 \mathrm{~V}$ \\
Cr target (Watt) & $0 \sim 200 \mathrm{~W}$ \\
Temperature & Room temp. \\
\hline
\end{tabular}

During PVD, the DC power connected to the sputter was controlled for Cr doping, while CVD was used to deposit the DLC films. Cr was deposited to its thickness of about $0.3 \mu \mathrm{m}$ as a buffer layer using the $\mathrm{Cr}$ target and DC power. Then, $\mathrm{Ar}$ and $\mathrm{C}_{2} \mathrm{H}_{2}$ gases and a $500 \mathrm{~V}$-DC pulsed power were applied to the substrate to deposit the DLC film on the buffer layer, while Cr-DLC was deposited by applying DC power at the same time. At this time, an increase in the $\mathrm{Cr}$ content increased the corrosion rate of the film because of the presence of the metal. Thus, in order to minimize the $\mathrm{Cr}$ content, the DC power was varied from 0 to $200 \mathrm{~W}$ while the shutter on the target was turned on and off after every 5 min. This resulted in the generation of the layered DLC and CR-DLC structures. The entire deposition process was carried out at room temperature. Figs. 1 and 2 show the schematic of the experimental set-up. Table 1 lists the process conditions. The total thickness of the Cr-DLC coating was fixed at approximately $1 \mu \mathrm{m}$ by adjusting the deposition time.

\subsection{Characterization}

The $\mathrm{Cr}$ content of the thin films was analyzed by electron probe micro analysis (EPMA). X-ray photoelectron spectroscopy (XPS) and Raman spectroscopy were used to investigate the changes in the structural properties of the thin films with the addition of Cr. Field-emission scanning electron microscopy (FE-SEM) was used to measure the thickness of the intermediate and the Cr-DLC layers of the deposited thin films. Electrical conductivity measurements and potentiodynamic polarization tests were carried out to investigate the chemical properties of the thin films. The electrical conductivity of the films was measured using a four-point probe system (CMT-SR1000N). The film deposited on the Si wafer was used as the specimen for this measurement. To evaluate the corrosion resistance of the $\mathrm{Cr}$ DLC thin films, a potentiodynamic polarization test was carried out on a specimen with the Cr-DLC thin film deposited on SUS304. An electrolyte with 2 ppm of hydrogen fluo- 
ride (HF) was added to $1 \mathrm{M}$ sulfuric acid $\left(\mathrm{H}_{2} \mathrm{SO}_{4}\right)$ at $80^{\circ} \mathrm{C}$ to create a high-temperature acidic atmosphere similar to that of polymer fuel cells. $\mathrm{Ag} / \mathrm{AgCl}$ and $\mathrm{Pt}$ were used as the reference and counter electrodes, respectively. From the polarization curves obtained by carrying out the potentiodynamic polarization tests, the corrosion resistance parameters such as the passive current density, passive potential, critical anodic current density, and formal potential of the thin films could be determined.

\section{Results and Discussion}

\subsection{Microstructure of the Cr-DLC films}

In order to control the $\mathrm{Cr}$ content of the Cr-DLC thin films, the DC power of the $\mathrm{Cr}$ target was varied from 0 to $200 \mathrm{~W}$. The cross-sections of the thin films were observed using FE-SEM (Fig. 3). The films showed a multi-layer morphology and had a thickness of approximately $1 \mu \mathrm{m}$. The elemental composition of the films was analyzed by EPMA. The changes in the $\mathrm{Cr}$ content of the films are shown in Fig. 4 , and the elemental compositions of the films are listed in

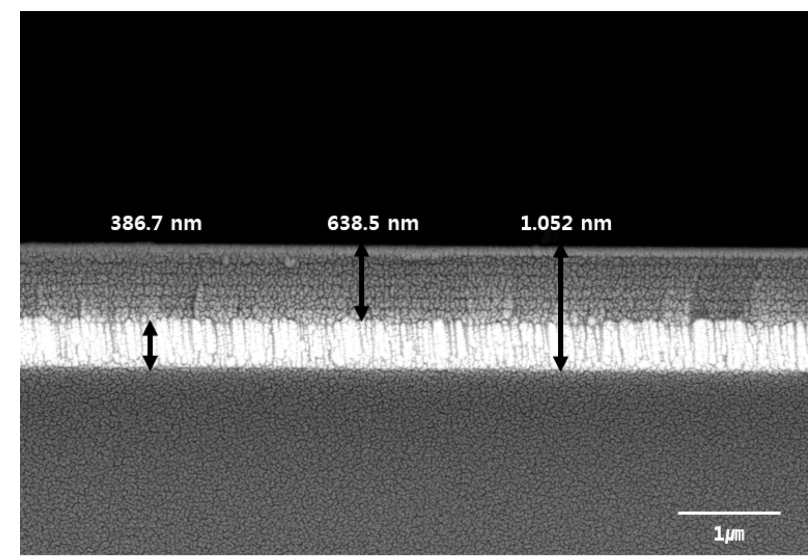

Fig. 3. FE-SEM image of the cross-section of the thin film.

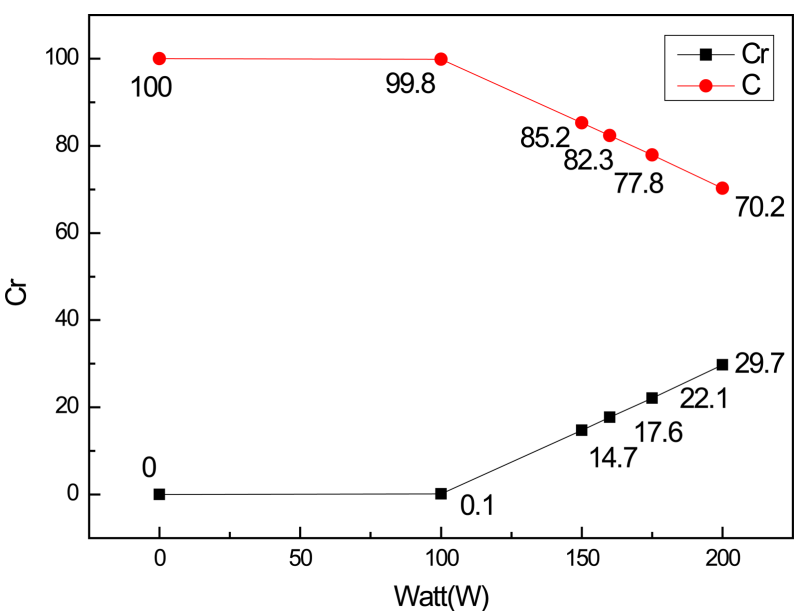

Fig. 4. EPMA curves for the Cr-DLC content with varying supplied power.
Table 2. EPMA Results for Carbon and Chromium Contents in Cr-DLC Thin Films

\begin{tabular}{cccc}
\hline Sample & Watt $(\mathrm{W})$ & C $(\%)$ & Cr $(\%)$ \\
\hline Pure DLC & 0 & 100 & 0 \\
$\# 1$ & 100 & 99.8 & 0.1 \\
$\# 2$ & 150 & 85.2 & 14.7 \\
$\# 3$ & 160 & 82.3 & 17.6 \\
$\# 4$ & 175 & 77.8 & 22.1 \\
$\# 5$ & 200 & 70.2 & 29.7 \\
\hline
\end{tabular}

Table 2. As can be observed from Fig. 4 and Table 2, the $\mathrm{Cr}$ peak began to appear at the DC power of $100 \mathrm{~W}$. With an increase in power, the $\mathrm{Cr}$ content of the films increased from 0 to 29.7 at\%. To minimize the $\mathrm{Cr}$ content, DC power was used for the deposition. However, because of the high sputtering yield of the equipment used in this study, $\mathrm{Cr}$ signals started appearing at $150 \mathrm{~W}$. Therefore, the minimum $\mathrm{Cr}$ content obtained by DC power was 14.7 at\%.

In order to investigate the structural characteristics and degrees of graphitization of the Cr-DLC thin films, Raman analysis was carried out. The G and D peaks of the films

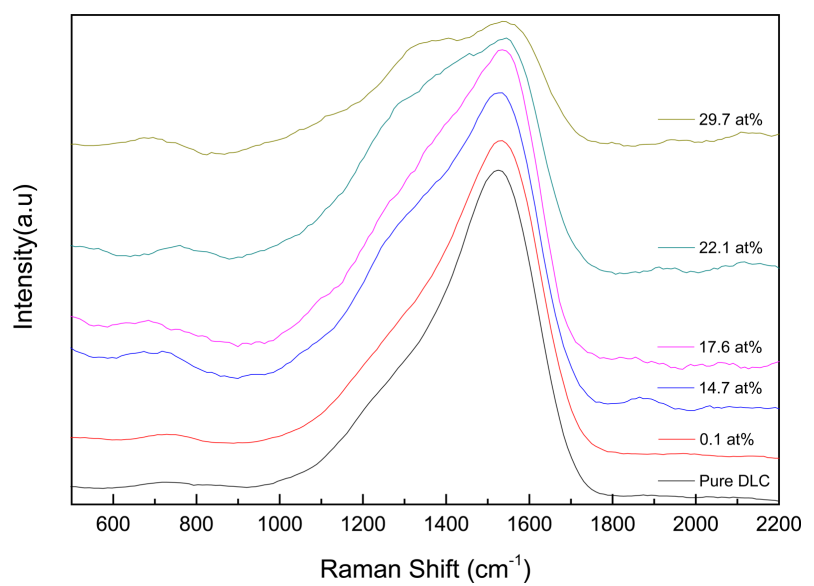

Fig. 5. Comparison of Raman spectral shift with $\mathrm{Cr}$ content.

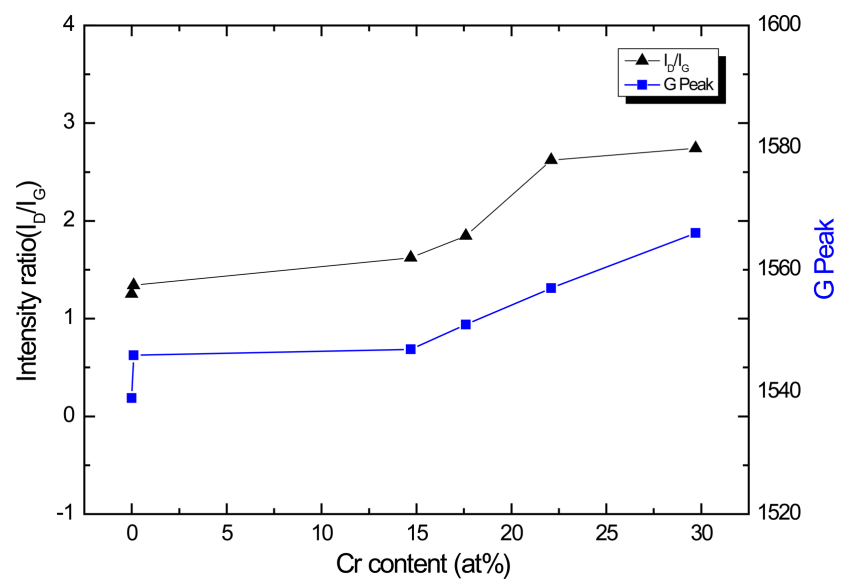

Fig. 6. $I_{D} / I_{G}$ position shift with $\mathrm{Cr}$ content. 
were separated by Gaussian curve fitting (Figs. 5 and 6). In graphite-based materials, the $\mathrm{G}$ peak is observed at approximately $1580 \mathrm{~cm}^{-1}$. Carbon structures with defects or substituted atoms show a strong D peak at approximately 1350 $\mathrm{cm}^{-1}{ }^{20)}$ DLC thin films are amorphous in nature. These films usually exhibit two peaks: a $\mathrm{G}$ peak at approximately $1550 \mathrm{~cm}^{-1}$ (lower than that of graphite) and a D peak at

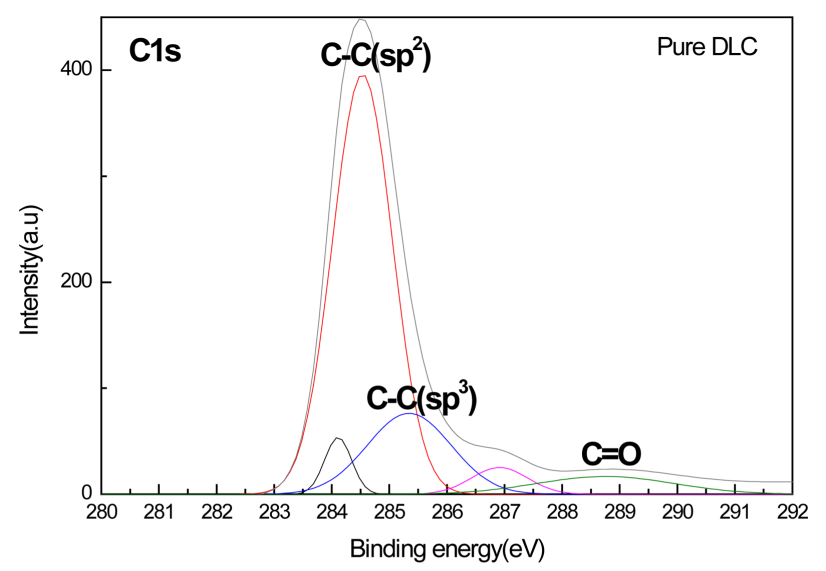

(a)

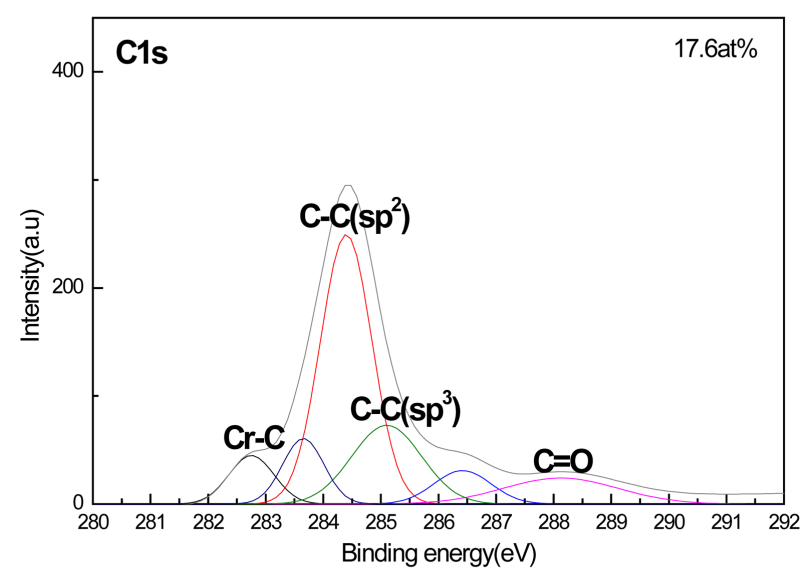

(b)

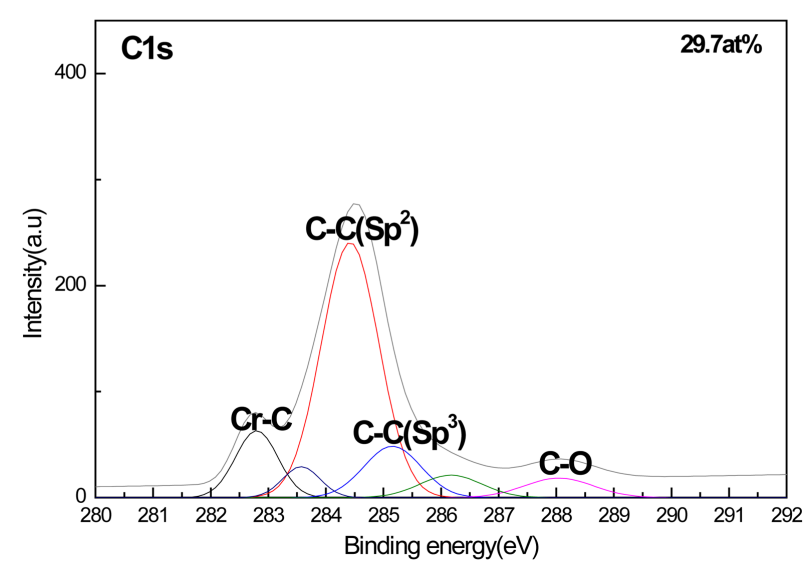

(c)

Fig. 7. C1s XPS profiles of Cr-DLC thin films of (a) Pure DLC (b) with 17.6 at\% of $\mathrm{Cr}$ and (c) 29.7 at\% of $\mathrm{Cr}$. approximately $1350 \mathrm{~cm}^{-1}$.

The $\mathrm{sp}^{2} / \mathrm{sp}^{3}$ ratio of thin films depends on their $\mathrm{I}_{\mathrm{D}} / \mathrm{I}_{\mathrm{G}}$ intensity ratio, which is determined from the Raman analysis. Thus, the crystallinity of thin films can be examined by carrying out their Raman analysis. ${ }^{20,21)}$ The higher the intensity ratio, the higher is the $\mathrm{sp}^{2}$ bond fraction of a thin film and vice versa. ${ }^{1,20-22)}$

The pure DLC thin films (without $\mathrm{Cr}$ ) showed a $\mathrm{G}$ peak at approximately $1536 \mathrm{~cm}^{-1}$ and a D peak at approximately $1353 \mathrm{~cm}^{-1}$ (Fig. 5). This is typical of thin films deposited by PECVD. However, with an increase in the $\mathrm{Cr}$ content, the $\mathrm{G}$ peak shifted toward the right. The $\mathrm{D}$ peak showed a significant shift at $\mathrm{Cr}$ contents $>22.1$ at\%. The shift in the D peak was caused by the defects or contaminants present in the crystal, and it can be deduced that the $\mathrm{Cr}$ content increased in this study. As shown in Fig. 6, the $\mathrm{I}_{\mathrm{D}} / \mathrm{I}_{\mathrm{G}}$ value increased gradually with an increase in the $\mathrm{Cr}$ content. The $\mathrm{I}_{\mathrm{D}} / \mathrm{I}_{\mathrm{G}}$ values of the thin films were inversely proportional to their $\mathrm{sp}^{2} /$ $\mathrm{sp}^{3}$ carbon atom ratios. This indicates that the addition of $\mathrm{Cr}$ resulted in a reduction in the $\mathrm{sp}^{3}$ bond fraction. With an increase in the $\mathrm{Cr}$ content, the $\mathrm{sp}^{2}$ bond fraction of the films increased, while the $\mathrm{sp}^{3}$ bond fraction decreased. In addi-

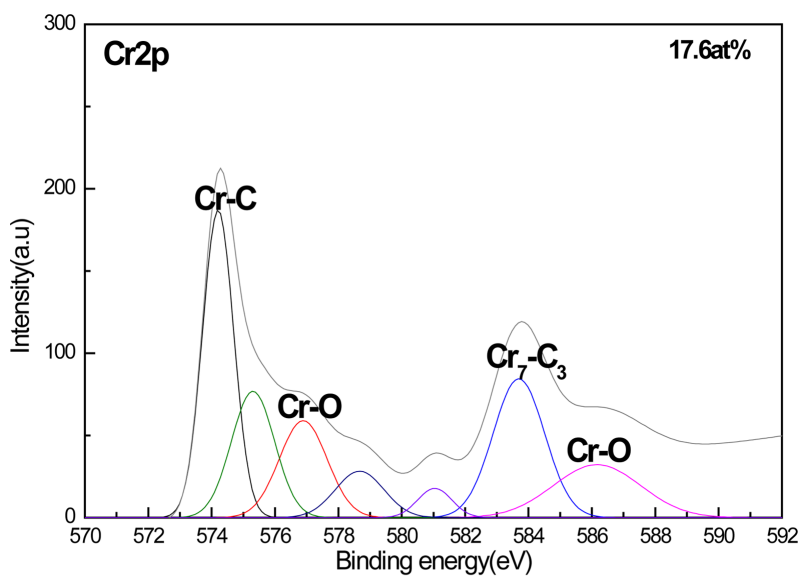

(a)

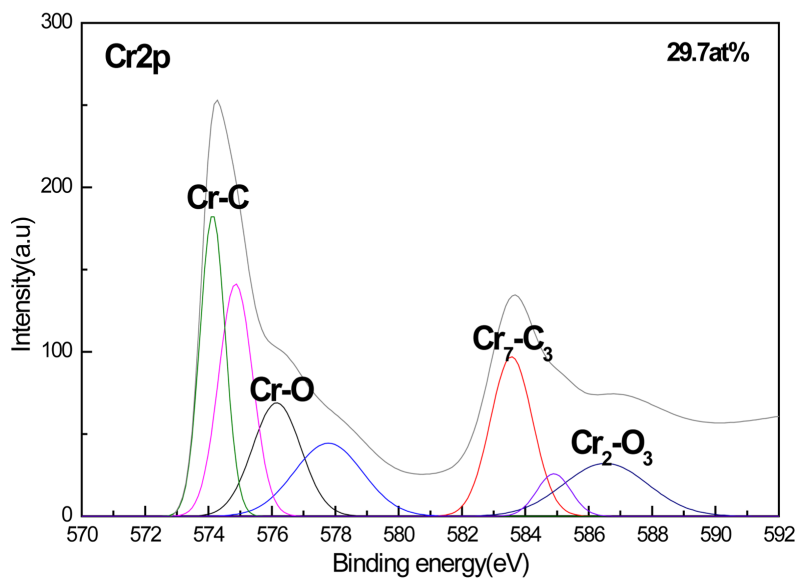

(b)

Fig. 8. Cr $2 p$ XPS profiles of Cr-DLC thin films with (a) 17.6 at $\%$ of $\mathrm{Cr}$ and (b) 29.7 at\% of $\mathrm{Cr}$. 
tion, the G peak shifted to higher wavenumbers with an increase in the Cr content.

XPS analysis was carried out to investigate the bonding state between $\mathrm{C}$ and $\mathrm{Cr}$ in the Cr-DLC thin films. DLC thin films deposited by the PECVD method show XPS peaks at $284.4\left(\mathrm{sp}^{2}\right)$ and $285.2\left(\mathrm{sp}^{3}\right) \mathrm{eV}$ corresponding to C-C bonds, $287.7 \mathrm{eV}$ corresponding to C-O bonds, and $288.4 \mathrm{eV}$ corresponding to $\mathrm{C}=\mathrm{O}$ bonds. ${ }^{23)}$ The XPS results analyzed by Gaussian curve fitting are shown in Figs. 7 and 8 (a, b, and c). Fig. 7(a) shows the XPS spectrum of the pure DLC thin film with peaks at $284.5\left(\mathrm{sp}^{2}\right), 285.3\left(\mathrm{sp}^{3}\right)$, and $288.6((\mathrm{C}=\mathrm{O})$ bonds) eV. Figs. 7(b) and (C) show the chemical bonds of the films with different $\mathrm{Cr}$ contents. These figures show peaks at $284.5\left(\mathrm{sp}^{2}\right), 285.3\left(\mathrm{sp}^{3}\right)$, and $288.6((\mathrm{C}=\mathrm{O})$ bonds $)$, which are similar to those shown in Fig. 7(a). However, with an increase in the $\mathrm{Cr}$ content, the intensity of the C-C ( $\left.\mathrm{sp}^{2}\right)$ bond decreased and a peak at $282.8 \mathrm{eV}$ corresponding to the $\mathrm{Cr}-\mathrm{C}$ bond appeared. This peak was not observed in the case of the pure DLC film. The intensity of the $282.8 \mathrm{eV}$ peak at the $\mathrm{Cr}$ content of 29.7 at\% was higher than that at the $\mathrm{Cr}$ content of 17.6 at\%. The peaks corresponding to the C-O and $\mathrm{C}=\mathrm{O}$ bonds observed in all the specimens can be attributed to the contamination caused by air.

As shown in Fig. 8(a), peaks at 574.2 (Cr-C), 575.3 (Cr-C), 576.9 (Cr-O), $583.7\left(\mathrm{Cr}_{7}-\mathrm{C}_{3}\right)$, and 586.2 ((Cr-O) bonds) $\mathrm{eV}$ were observed. Fig. 8(b) shows the presence of $\mathrm{Cr}-\mathrm{C}$ (574.1 and , $574.9 \mathrm{eV}), \mathrm{Cr}-\mathrm{O}(576.15 \mathrm{eV}), \mathrm{Cr}_{7}-\mathrm{C}_{3}(583.6 \mathrm{eV})$, and $\mathrm{Cr}_{2}-\mathrm{O}_{3}(586.54 \mathrm{eV})$ bonds. From Figs. 8(a) and (b), it can be observed that the peak corresponding to the Cr-C bond $(574.2 \mathrm{eV})$ showed the highest intensity. This is consistent with the $\mathrm{C} 1 \mathrm{~s}$ results of the films. Moreover, it can be observed that the intensity of the $\mathrm{Cr}-\mathrm{C}$ bond peak $(574.8 \mathrm{eV})$ at the $\mathrm{Cr}$ content of 29.7 at\% was higher than that at the $\mathrm{Cr}$ content of 17.6 at\%. This confirms that the C-C bond fraction $\left(\mathrm{sp}^{2}\right)$ decreased with an increase in the $\mathrm{Cr}-\mathrm{C}$ bond fraction. This is because $\mathrm{Cr}$ easily combines with $\mathrm{C}-\mathrm{C}$ bonds $\left(\mathrm{sp}^{2}\right)$ to form the Cr-C phase owing to the relatively lower binding energy of $\mathrm{sp}^{2} \mathrm{C}-\mathrm{C}$ bonds than that of $\mathrm{sp}^{3} \mathrm{C}-\mathrm{C}$ bonds. $^{23)}$

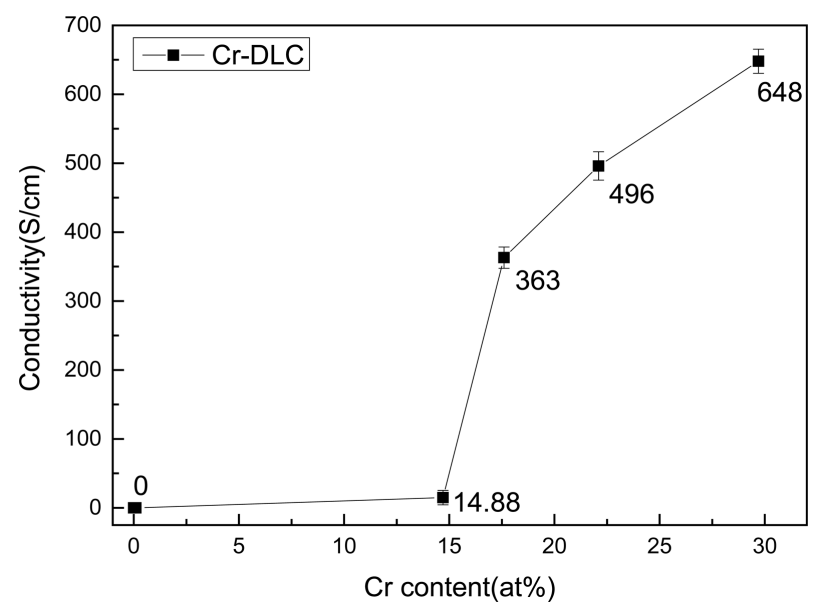

Fig. 9. Electrical conductivity curve with varying $\mathrm{Cr}$ content.

\subsection{Chemical properties of the Cr-DLC films}

The effect of the $\mathrm{Cr}$ content on the electrical conductivity of the Cr-DLC thin films was investigated. As shown in Fig. 9, the films showed electrical conductivity at $\mathrm{Cr}$ contents of 14.7 at\% or more. For the films with $\mathrm{Cr}$ contents $<14.7$ at\%, the electrical conductivity was not measured by the fourpoint probe system. The electrical conductivity of the film with the Cr content of 17.6 at\% was approximately 25 times higher than that of the film with the Cr content of 14.7 at\%. Therefore, the electrical conductivity analysis revealed that the Cr-DLC films grown on the Si substrate showed electrical conductivity only at $\mathrm{Cr}$ contents higher than 17.6 at\%. The corrosion resistance of the Cr-DLC films prepared in this study was compared with that of Ti-DLC films. The TiDLC film showed an electrical conductivity of $680 \mathrm{~S} / \mathrm{cm}$ at the Ti content of 18 at\%. Hence, it can be stated that TiDLC films show higher electrical conductivity than Cr-DLC films at the same metal loading. This indicates that $\mathrm{Ti}$ is more suitable for doping DLC films than $\mathrm{Cr}$.

Since metals tend to ionize, they decrease the corrosion resistance of DLC films. To mitigate this, it is imperative to develop a novel thin film deposition technique for preparing DLC films with high electrical conductivity and corrosion resistance. Therefore, we investigated the polarization behavior of the Cr-DLC thin films to evaluate their corrosion characteristics. The passive current density, passive potential, critical anodic current density, and formal potential of the Cr-DLC thin films could be determined from their polarization curves. The corrosion resistance of the Cr-DLC films could also be evaluated from their polarization curves. The lower the corrosion potential of a thin film, the higher is its current density and the more is the corrosion. Fig. 10 and Table 3 show the results of the potentiodynamic polarization test. As can be observed, the pure DLC film showed the highest current density and corrosion potential, and hence showed good corrosion resistance. The DLC films with $\mathrm{Cr}$ contents of $0.1-17.6$ at\% showed corrosion resistance similar to that of the pure DLC film. The corrosion

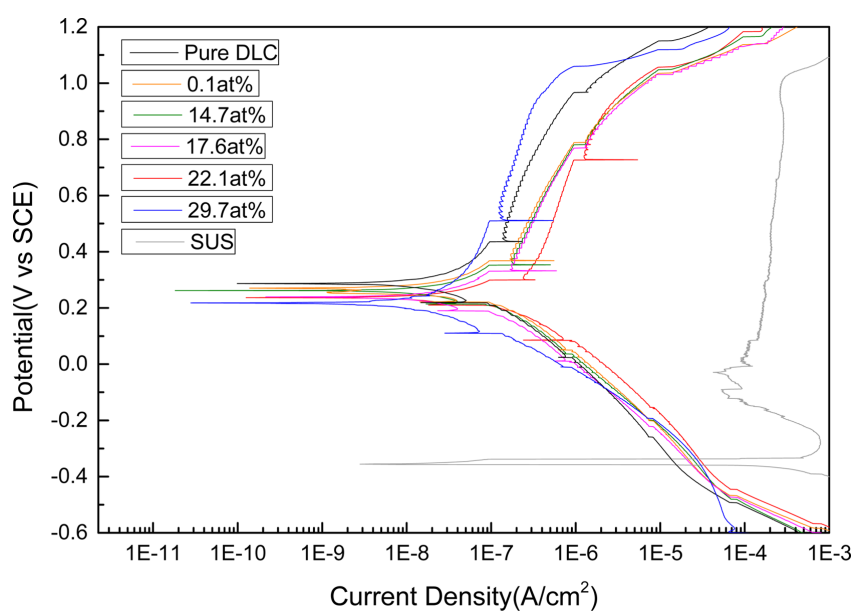

Fig. 10. Potentiodynamic polarization curves of Cr-DLC thin films with varying $\mathrm{Cr}$ content. 
Table 3. Current Density and Corrosion Potential Values of Cr-DLC Thin Films with Varying Cr Content

\begin{tabular}{ccc}
\hline Sample & $\begin{array}{c}\text { Current density } \\
\left(\mathrm{A} / \mathrm{cm}^{2}\right)\end{array}$ & $\begin{array}{c}\text { Corrosion potential } \\
(\mathrm{V})\end{array}$ \\
\hline SUS & $4.81 \times 10^{-4}$ & 0.357 \\
Pure DLC & $2.56 \times 10^{-8}$ & 0.288 \\
Cr 0.1 at\% & $9.42 \times 10^{-8}$ & 0.269 \\
Cr 14.7 at\% & $9.38 \times 10^{-8}$ & 0.262 \\
Cr 17.6 at\% & $9.12 \times 10^{-8}$ & 0.240 \\
Cr 22.1 at\% & $1.84 \times 10^{-8}$ & 0.241 \\
Cr 29.7 at\% & $1.21 \times 10^{-7}$ & 0.212 \\
\hline
\end{tabular}

resistance decreased gradually when the $\mathrm{Cr}$ content exceeded 22.1 at\%. The film with the $\mathrm{Cr}$ content of 17.6 at\% showed a current density of $9.12 \times 10^{-2} \mu \mathrm{A} / \mathrm{cm}^{2}$ and a corrosion potential of $0.240 \mathrm{~V}$, which are similar to those of the pure DLC film. The film also showed excellent corrosion resistance and electrical conductivity. The Ti-DLC film showed the highest current density of $2.5 \times 10^{-2} \mu \mathrm{A} / \mathrm{cm}^{2}$ and corrosion potential of $0.242 \mathrm{~V}$ at the Ti content of 15 at\%. Hence, the Cr-DLC films showed better corrosion resistance than the Ti-DLC films.

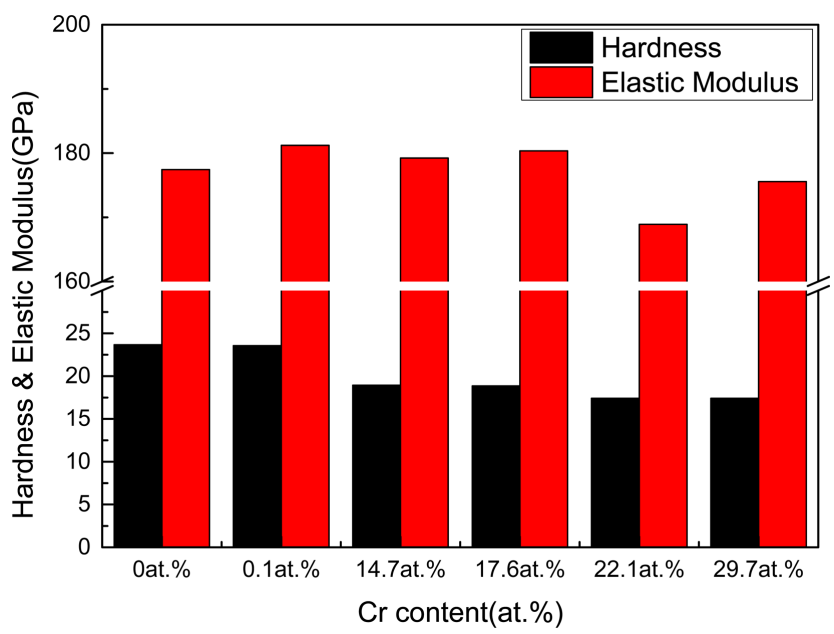

Fig. 11. Hardness and elastic modulus with varying $\mathrm{Cr}$ content.

Table 4. Hardness and Elastic Modulus with Varying $\mathrm{Cr}$ Content

\begin{tabular}{ccccc}
\hline & $\begin{array}{c}\text { Hardness } \\
(\mathrm{GPa})\end{array}$ & $\begin{array}{c}\text { Hardness } \\
\text { deviation }\end{array}$ & $\begin{array}{c}\text { Elastic } \\
\text { modulus } \\
(\mathrm{GPa})\end{array}$ & $\begin{array}{c}\text { Elastic } \\
\text { modulus } \\
\text { deviation }\end{array}$ \\
\hline DLC & 23.6 & 1.3 & 177.4 & 6.2 \\
0.1 at\% & 23.5 & 1.4 & 181.2 & 5.4 \\
14.7 at\% & 18.9 & 1.3 & 179.2 & 5.1 \\
17.6 at\% & 18.8 & 0.4 & 180.3 & 1.1 \\
22.1 at\% & 17.4 & 1.3 & 168.9 & 5.2 \\
29.7 at\% & 17.4 & 0.9 & 175.5 & 4.5 \\
\hline
\end{tabular}

\subsection{Mechanical properties of the Cr-DLC films}

The hardness of the Cr-DLC thin films deposited on the Si-wafer was measured using a nanoindenter (MTS XP, Helmut Fischer). Fig. 11 and Table 4 show the hardness of the Cr-DLC films as a function of the $\mathrm{Cr}$ content. The pure DLC film showed a hardness value of $23.6 \mathrm{GPa}$, which decreased with the addition of $\mathrm{Cr}$. The film with the $\mathrm{Cr}$ content of 17.6 at\% showed a hardness value of $18.8 \mathrm{GPa}$. On the other hand, the Ti-DLC film with the Ti content of 18 at\% showed a hardness value of $25.6 \mathrm{GPa}$. This indicates that the Ti-DLC films were harder than the Cr-DLC films.

The abrasion test was carried out using a tribometer (Ball-on-disk type, J\&L Tech) to investigate the wear characteristics of the Cr-DLC thin films with different $\mathrm{Cr}$ con-

Table 5. Conditions for Dry Wear Test

\begin{tabular}{cc}
\hline & Wear test conditions \\
\hline Test type & Ball-on-disk \\
Ball type & SUJ2 \\
Distance & $300 \mathrm{~m}$ \\
Load & $5 \mathrm{~N}$ \\
Linear speed & $100 \mathrm{~mm} / \mathrm{s}$ \\
Temperature & Room temperature \\
\hline
\end{tabular}

Table 6. Conditions for Oil Wear Test

\begin{tabular}{cc}
\hline & Wear test conditions \\
\hline Test type & Ball-on-disk \\
Ball type & SUJ2 \\
Distance & $300 \mathrm{~m}$ \\
Load & $5 \mathrm{~N}$ \\
Linear speed & $100 \mathrm{~mm} / \mathrm{s}$ \\
Oil & GF4 Oil \\
Temperature & Room temperature \\
\hline
\end{tabular}

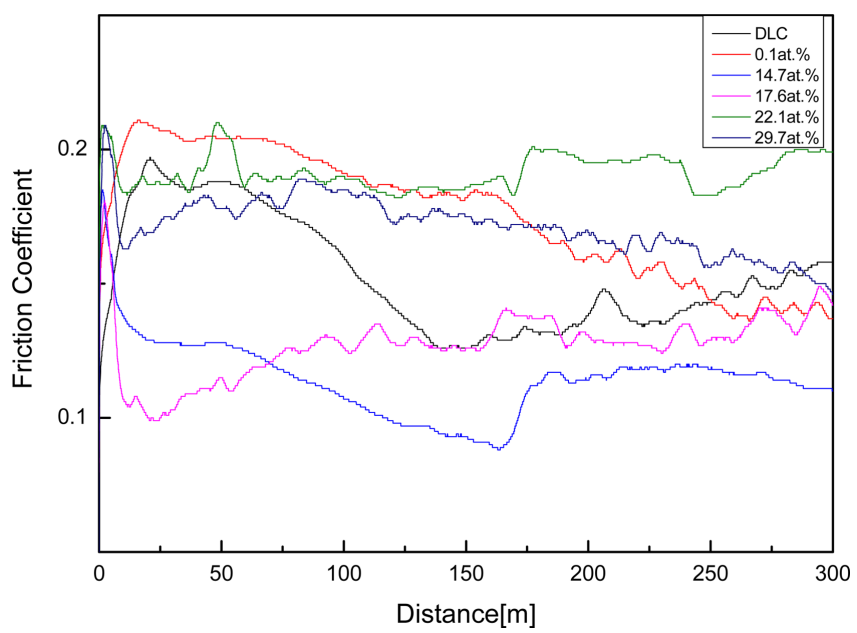

Fig. 12. Friction coefficient of Cr-DLC thin films with varying $\mathrm{Cr}$ content under dry conditions. 


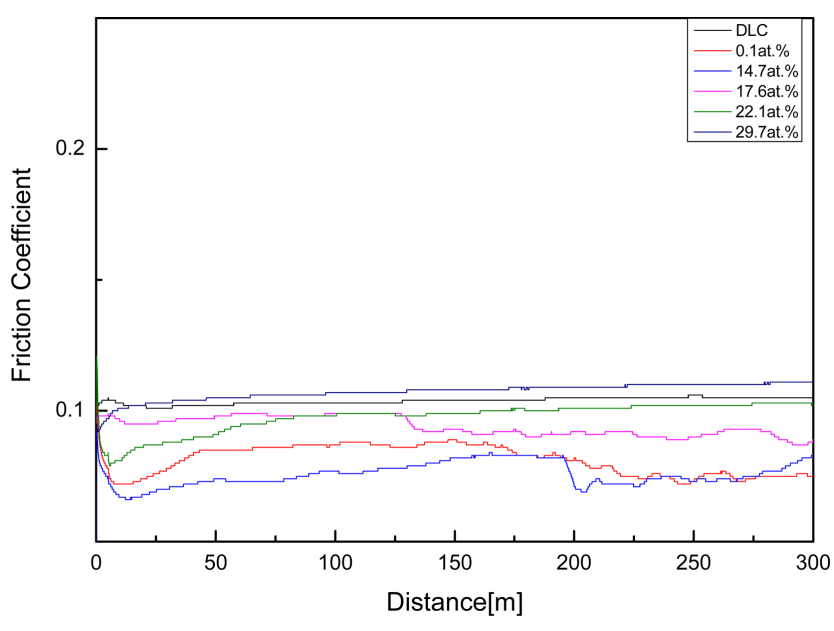

Fig. 13. Friction coefficient of Cr-DLC thin films with varying $\mathrm{Cr}$ content under lubrication conditions.

tents. The wear characteristics of the films were investigated under both dry and lubrication conditions. GF4 oil was used for lubrication. GF4 oil is a next-generation automotive engine oil for reducing the friction of automotive-driven parts. However, since GF4 oil destroyed the initial DLC film, it was used to examine the damage of the thin films. Therefore, wear tests were carried out using GF4 oil, and the damage of the Cr-DLC thin films was observed after the wear tests. The dry and lubrication wear test conditions are summarized in Tables 5 and 6, respectively. The corresponding test results are shown in Figs. 12 and 13, respectively. The wear test results revealed that under the dry condition, the Cr-DLC thin films showed a friction coefficient of $0.11-0.19$, which is comparable to that of the pure DLC thin films (Fig. 12). The DLC films with Cr contents of 14.7 and 17.6 at\% showed higher friction coefficients than the pure DLC films (0.11-0.12). The film with the Cr content of 14.7 at\% showed the best wear characteristics. This indicates that moderate $\mathrm{Cr}$ doping is optimum for developing DLC films with good wear characteristics. The abrasion of the films under the dry condition was investigated using an optical microscope (Fig. 14). Since the lubrication condition yielded low coefficients of friction, it was difficult to observe the abrasion track of the films under this condition. Therefore, wear tracks were observed only under the dry condition. The wear track width of the pure DLC film was about $96 \mu \mathrm{m}$, while that of the DLC films with Cr contents of 17.6 and 29.7 at\% was found to be about $195 \mu \mathrm{m}$. As can be observed from Fig. 14, the surface of the Cr-DLC films easily damaged because of the decrease in their hardness with an increase in the $\mathrm{Cr}$ content. Under the lubrication condition, the Cr-DLC films showed friction coefficients of 0.07-0.1, which are similar to those of the pure DLC films (Fig. 13). The coefficient of friction of the films increased slightly with the addition of Cr. In addition, GF4 oil caused no damage to the thin films. In previous studies, Ti-DLC thin films were not damaged by GF4 oil and showed a friction coefficient of 0.2 under dry conditions. The friction coef-

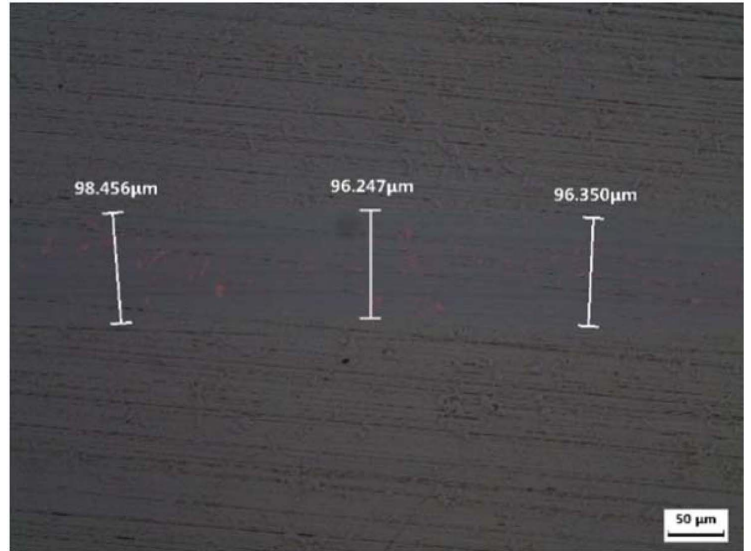

(a)

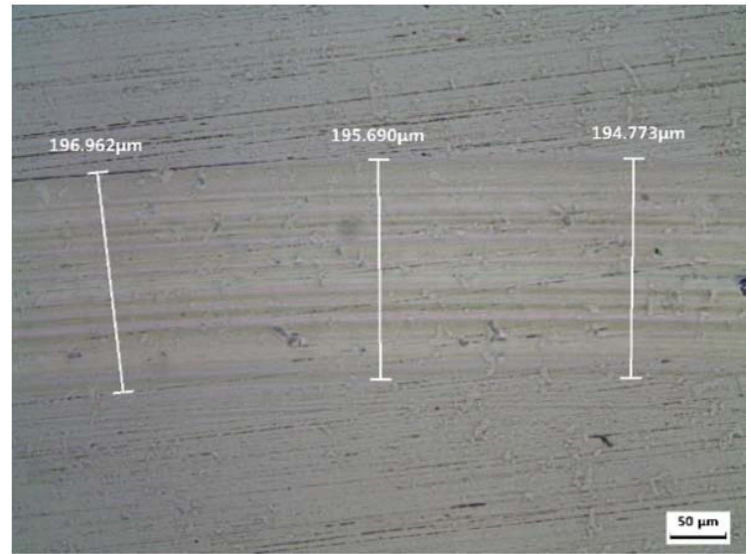

(b)

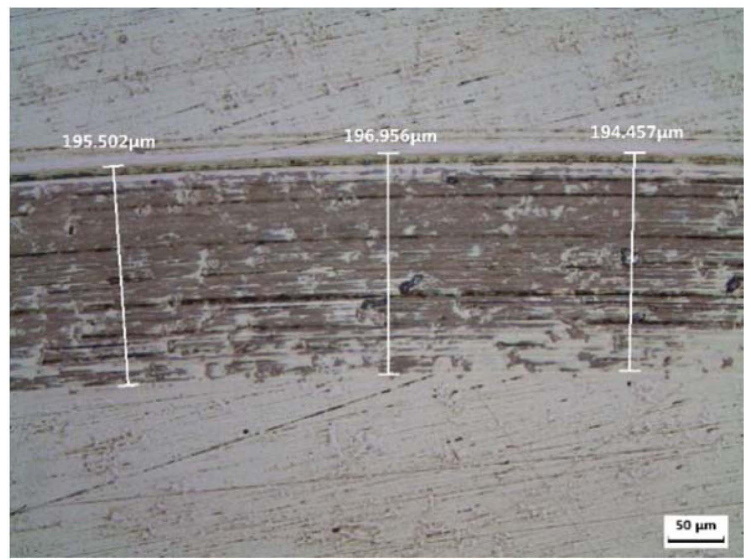

(c)

Fig. 14. Optical microscopy images of wear tracks in dry condition for (a) Pure DLC (b) 17.6 at\% of $\mathrm{Cr}$ and (c) 29.7 at $\%$ of $\mathrm{Cr}$.

ficients of the Cr-DLC films were about the double of the previously reported Ti-DLC films.

\section{Conclusions}

The structural and chemical properties of Cr-DLC thin films deposited using a hybrid method were investigated. 
The Cr content of 17.6 at\% was found to be optimum for achieving good electrical conductivity and corrosion resistance. Under high-temperature acidic conditions, the $\mathrm{Cr}$ DLC thin films showed higher corrosion resistance than the Ti-DLC films at room temperature. In addition, the $\mathrm{Cr}$ addition improved the wear characteristics of the DLC thin films by about two times. The Cr-DLC films showed better wear characteristics than the Ti-DLC films. The findings of this study will be useful for developing various automobile parts and separators.

\section{Acknowledgments}

This work was supported by the Human Resources Development Program (No. 20174030201830) of the Korea Institute of Energy Technology Evaluation and Planning (KETEP) funded by the Korean Government Ministry of Trade, Industry and Energy, the National Research Foundation of Korea (NRF) funded by the Korean government (Ministry of Education) (No. NRF-2016R1D1A1A02936936), and a grant from the Industrial R\&D Program for Core Technology of Materials funded by the Ministry of Trade, Industry, and Energy (10048043, Development of low friction coating components of combustion engine for correspondence of fuel economy regulation), Republic of Korea.

\section{REFERENCES}

1. J. Robertson, "Diamond-like Amorphous Carbon," Mater. Sci. Eng. R, 37 [4-6] 129-281 (2002).

2. Z. Has, S. Mitura, and M. Clapa, "Electrical Properties of Thin Carbon Films Obtained by R.F. Methane Decomposition on an R.F.-powered Negatively Self-biased Electrode," Thin Solid Films, 136 [2] 161-66 (1986).

3. A. Tanaka, "Development of Various Hard Carbon Films and Their Tribological Properties," New Diamond Front. Carbon Technol., 14 [3] 149-60 (2004).

4. E. Staryga and G. W. Bak, "Relation between Physical Structure and Electrical Properties of Diamond-like Carbon Thin Films," Diamond Relat. Mater., 14 [1] 23-34 (2005).

5. C. Donnet, "Advanced Solid Lubricant Coatings for High Vacuum Environments," Surf. Coat. Technol., 80 [1-2] 151-56 (1996).

6. H. W. Choi, J. H. Choi, K. R. Lee, J. P. Ahn, and K. H. Oh, "Structure and Mechanical Properties of Ag-Incorporated DLC Films Prepared by a Hybrid Ion Beam Deposition System," Thin Solid Films, 516 248-51 (2007).

7. K. W. Whang and H. S Tae, "The Properties of Diamondlike Carbon Films Prepared by R.f. Discharges," Thin Solid Films, 204 [1] 49-58 (1991).

8. A. Grill and B. Meyerson, "Development and Status of Diamondlike Carbon," pp. 91-141 in Synthetic Diamond: Emerging CVD Science and Technology, Ed. by K. E. Spear, and J. P. Dismukes, Wiley, New York, 1994.

9. A. Grill, "Tribology of Diamondlike Carbon and Related Materials: An Updated Review," Surf. Coat. Technol., 94-
95 507-13 (1997)

10. D. J. Li, F. Z. Cui, and H. Q. Gu, "Studies of Diamond-like Carbon Films Coated on PMMA by Ion Beam Assisted Deposition," Appl. Surf. Sci., 137 [1-4] 30-7 (1999).

11. J. C. Sanchez-Lopez, C. Donnet, J. Fontaine, M. Belin, A. Grill, V. Patel, and C. Jahnes, "Diamond-like Carbon Prepared by High Density Plasma," Diamond Relat. Mater., 9 [3-6] 638-42 (2000).

12. C. S. Lee, K. R. Lee, K. Y. Eun, K. H. Yoon, and J. H. Han, "Structure and Properties of Si Incorporated Tetrahedral Amorphous Carbon Films Prepared by Hybrid Filtered Vacuum Arc Process," Diamond Relat. Mater., 11 [2] 198203 (2002)

13. G. Thorwarth, C. Hammerl, M. Kuhn, W. Assmann, B. Schey, and B. Stritzker, "Investigation of DLC Synthesized by Plasma Immersion Ion Implantation and Deposition," Surf. Coat. Technol., 193 [1-3] 206-12 (2005).

14. K. Chakrabarti, M. Basu, S. Chaudhuri, A. K. Pal, and H. Hanzawa, "Mechanical, Electrical and Optical Properties of a-C:H:N Films Deposited by Plasma CVD Technique," Vacuum, 53 [3-4] 405-13 (1999).

15. K. S. Shim, S. M. Kim, S. H. Bae, S. Y. Lee, H. S. Jung, and H. H. Park, "Fabrication and Characterization of Diamond-like Carbon Thin Films by Pulsed Laser Deposition," Appl. Surf. Sci., 154-155 482-84 (2000).

16. Y. H. Jun, "Diamond-like Carbon Film (in Korean)," Phys. High Technol., 12 [3] 9-14 (2003).

17. B. Bhushan, "Chemical, Mechanical and Tribological Characterization of Ultra-Thin and Hard Amorphous Carbon Coatings as thin as $3.5 \mathrm{~nm}$ : Recent Developments," Diamond Relat. Mater., 8 [11] 1985-2015 (1999).

18. J. H. Kim, "Commercializing Technology Development of Bipolar Plates for Polymer Electrolyte Membrane Fuel Cell (in Korean)," Trans. Korean Hydrogen New Energy Soc., 22 [3] 409-14 (2011).

19. D. S. Jang and J. J. Lee, "Corrosion Properties of CarbonCoated Metallic Bipolar Plate for PEMFC (in Korean)," J. Korean Inst. Surf. Eng., 48 [3] 87-92 (2015).

20. A. C. Ferrari, J. C. Meyer, V. Scardaci, C. Casiraghi, M. Lazzeri, F. Mauri, S. Piscanec, D. Jiang, K. S. Novoselov, S. Roth, and A. K. Gelm, "Raman Spectrum of Graphene and Graphene Layers," Phys. Rev. Lett., 97187401 (2006).

21. Y. Ishikawa, Y. Yamamoto, T. Hatayama, Y. Uraoka, and T. Fuyuki, "Crystallographic Analysis of High Quality Poly-Si Thin Films Deposited by Atmospheric Pressure Chemical Vapor Deposition," Sol. Energy Mater. Sol. Cells, 74 [1-4] 255-60 (2002).

22. J. Zi, H. Buscher, C. Falter, W. Ludwig, K. Zhang, and X. Xie, "Raman Shifts in Si Nanocrystals," Appl. Phys. Lett., 69 [2] 200-2 (1996).

23. P. Merel, M. Tabbal, M. Chaker, S. Moisa, and J. Margot, "Direct Evaluation of the $\mathrm{sp}^{3}$ Content in Diamond-likeCarbon Films by XPS,” Appl. Surf. Sci., 136 [1-2] 105-10 (1998).

24. G. F. Huang, Z. Lingping, H. Weiqing, Z. Lihua, L. Shaolu, and L. Deyi, "The Mechanical Performance and Anticorrosion Behavior of Diamond-like Carbon Film," Diamond Relat. Mater., 12 [8] 1406-10 (2003). 